\title{
HERINNERING AAN DR. J. PIJNAPPEL GzN.
}

A. C. VREEDE.

De omstandigheid dat Pijnappel gedurende een negental jaren Secretaris van het Instituut is geweest, en de "Bijdragen" met menig opstel van zijne hand verrijkt heeft, is een gereede anleiding om hier nog eens zijne geschriften en werken op het gebied der Taal-, Land- en Volkenkunde van Nederlandsch Indië te bespreken.

Hij was zelfs de eerste Secretaris, en met welken ijver hij zijne taak opvatte kan blijken uit de door hem opgestelde jaarverslagen, die getuigen van liefde voor het jong opgerichte Genootschap en de zucht om deszelfs bloei te bevorderen, ook en vooral om het dienstbaar te maken aan de wetenschap.

In den $3^{\text {den }}$ jaargang leverde hij niet minder dan 5 opstellen.

Reeds had Veth gewezen op de behoefte aan een goed schema der Geschiedenis van Ned. Indië. Toen nu Pijnappel geroepen werd om an de Koninklijke Academie te Delft ook Geschiedenis van Ned. Indië te doceeren achtte hij het noodig bij zijne lessen als leiddraad een "Overzigt van de Geschiedenis der Nederlanders in O. I." te geven. Aangaande dit overzicht, het eerste dezer opstellen, ontving ik van bevoegde zijde de volgende beoordeeling:

"De schrijver schreef in 1853 , en men moet den tact loven waar"mee hij, - ofschoon hij geen historicus was" of, zooals hij zelf zegt, wezen wilde - "toch een verdeeling in tijdvakken voor de "geschiedenis der Nederlanders in Oost-Indië voorstelt, die met "den werkelijken gang der historische ontwikkeling in overeen"stemming is. Zijn klare geest wilde toen reeds orde scheppen op "een gebied, waar ook nog later het gevaar van door de boomen "het bosch niet te zien zoo groot bleek. Klaar en duidelijk is hij " ook in zijn wijze van voorstelling. Een stap verder op den weg " van het eigenlijk historisch onderzoek brengt dit artikel ons niet, "doch niemand die zich dat minder voorstelt dan de schrijver zelf."

6e Volgr. $X$. 
Dit opstel werd gevolgd door een ander, getiteld: " B Bijdragen tot de kennis der geheime genootschappen van de Chineezen", bepaaldelijk het Hemel-Aarde-Verbond. In een vorigen jaargang had Hoffmann dat onderwerp behandeld, doch na kennisneming van een artikel in het "Journal of the Indian Archipelago and Eastern Asia" bevattende namelijk eene Engelsche vertaling van een gebeurtenis die den bekenden Maleischen auteur Abdullah overkwam en die hij in zijne Hikajat beschrijft, vond Pijnappel het noodig, mogelijk in het belang der rust van onze Koloniën ', daarop terug te komen. $\mathrm{Hij}$ had daarbij tevens gelegenheid de Engelsche vertaling hier en daar zachtkens te castigeeren en op het minder geloofwaardige van A.'s verhaal met het oog op tijds- en plaatsbepaling te wijzen (zie noot bij bl. 138).

Verder besprak hij daarin de Ethnologische Studiën van Earl ${ }^{2}$; het door dezen naar aanleiding van den haardos der Papoea's als ethnologisch criterium vooropgestelde kenmerk van het "haar" onderwierp hij aan een scherpzinnige en amusante beschouwing en toonde aan tot welke curieuse gevolgtrekkingen het aannemen van een dergelijk onderscheidingsteeken moet leiden; liever zou hij daarbij willen gebruik maken van de "taal". Hij geeft dan ook eenige etymologische beschouwingen over de woorden "Papoea" en "Alfoeren". In hetzelfde deel gaf hij eene hoofdzakelijk geographische Inleiding op eene Bijdrage van den heer Fabritius: Eenige bijzonderheden omtrent de Papoea's van de Geelvinksbaai van Nieuw Guinea.

Pijnappel's zienswijze omtrent het woord "Papoea" vond in den heer van Hoëvell, een kenner bij uitnemendheid van taal, land en volk van het oostelijkste gedeelte van onzen archipel, een krachtigen steun ${ }^{3}$.

Voorts deed Pijnappel in dat jaar een verdienstelijk werk door zijne Inhoudsopgaven van het Tijdschrift van Ned. Indië, van de Verhandelingen van het Bataviaasch Genootschap, enz.

De kennisneming van bescheiden, deel uitmakende der besehrijving

1 James Brooke Radja van Serawak vond het noodig op het gevaar te wijzen en er tegen te waarschuwen dat de kwade invloed van het Chineesche geheime genootsehap van Singapore naar Serawak kon overslaan, zie bl. $143 \mathrm{vlg}$.

2 The native races of the Indian Archipelago. Papuans. By George Windsor Earl. Lond. 1853.

3 Over de beteekenis van het woord Papoea of Papoewa door G. W. W. C. baron van Hoëvell Bijdr. 4, IV, 525, 526 . 
van Reinwardt's reis in de Molukken 1, stelde Pijnappel in staat een "gaping aan te vulleu" in de geschiedenis van de uitbarstingeu der vulkanen op Ternate. Hij deed daarvan mededeeling in de Bijdragen van 1859 en voegde daaraan de noodige Aanteekeningen toe.

- In Bijdr. 1860 trok Pijnappel tegen het voor de Maleische taal ondoelmatige en gebrekkige van het Arabische alphabet te velde, en toonde zich voorstander van het denkbeeld om dit door het Latijnsche te vervangen. Cohen Stuart hierop antwoordende betoogt dat Pijnappel in gebreke is gebleven de uitvoerbaarheid van dat voorstel aan te toonen of de middelen daartoe aan te geven, hoewel erkennende, dat zijne grieven gegrond zijn en dat hij een helder denkbeeld (geeft) van de wijze waarop de Arb. Mal. orthographie zich gevormd heeft. Tijdschrift Ind. T. L. V. 4, III, 111 vlg.

Deze taalkundige bijdrage wordt onmiddellijk gevolgd door eene (vooral) ethno-geographische "Beschrijving van het W. gedeelte der Z. en O. afd. van Borneo" hoofdzakelijk ontleend aan rapporten van den heer von Gaffron door den heer Weddik, toen (1853) Gouverneur van dat eiland, daarheen gezonden. Ook deze bewerking geeft blijk van Pijnappel's oordeel en belezenheid.

In den jaargang 1870 vinden wij vooreerst Pijnappel's Aantt. bij Klinkerts' Supplement op zijn Mal. Wdb. (zie daarover hier beneden) onmiddellijk gevolgd door eene Verhandeling "Ptolemaeus en de Indische Archipel" waarbij zich aansluit in Bijdr. 1872 een opstel "over de kennis, die de Arabieren voor de komst der Portugezen van den Ind. archipel bezaten".

Over het min of meer belangrijke dezer studie zal ik mij geen oordeel aanmatigen - dit moet ik aan meer bevoegden overlaten doch ik meen te mogen zeggen, dat het stilzwijgen omtrent deze Verhandeling in de Encyclopaedie van Ned. Indië, waar de literatuur betreffende den naamsoorsprong "Java" vermeld wordt, niet correct is. Aangenomen al, dat Pijnappel in zijn argumentatie tegen de verklaring van "Java" uit "Yawa Dwipa" te kort geschoten is (men kan die vinden bl. 62 vlg.) zoo mag toch ook hier gelden "audi et alteram partem".

Bovendien schrijft Pijnappel (1870) nog verder: "en zoo vinden wij dan in de latere Arabische berichten datzelfde $\mathrm{Jabadioe}$ in

1 Door hem uitgegeven onder den titel: Reinwardt's reis naar het Oostelijk gedeelte van den Indisehen Arohipel in het jaar 1821, Amsterdam 1858. 
Zabedj verbasterd en van een rijk van den $\mathrm{Z}$ abedj gewag gemaakt, dat verscheidene eilanden omvatte, ... en was het niet maar alleen Java, dat dien naam droeg.... Zoo was bv. Sumatra ook een Klein Java .... bij Marco Polo heet Sumatra Java Minor."

En wat geeft nu de auteur van het artikel Java, in de Encyclopaedie, Geschiedenis van dat eiland, wijlen de heer J. A. v. d. Broek hoogleeraar te Delft, met totale verzwijging van Pijnappel's uiteenzetting :

In de Sanskrit-litteratuur van het begin onzer jaartelling is Java (misschien ook Sumatra), zie Kern, Bijdr. 3, IV, 638, bekend als Y a w a Dwipa, een naam die waarschijnlijk "giersteiland " beteekent (Kern, Bijdr. 3, VI, 116) en door Ptolomaeus als Jabadioe, gersteneiland, wordt teruggegeven. De benaming $\mathrm{Dj}$ awa, ook aan Java gegeven, duidt echter niet altijd uitsluitend dit eiland aan. Zeker is het, dat ook Sumatra vroeger en ook nu nog wel $\mathrm{Dj}$ a wa K etjil (klein, oneigenlijk Djawa) genoemd, oudtijds ook bij Arabische schrijvers eveneens als Djawa bekend stond (van der Lith in Merveilles de l'Inde bl. 236) misschien ook omdat men zich vroeger beide eilanden als vereenigd voorstelde. De Arabische benaming $\mathrm{Z}$ a bedj heeft stellig op Java betrekking (Merveilles 231).

In hetzelfde jaar nog gaf Pijnappel een Catalogus van de Mal. handschriften der Leidsche Bibliotheek, die waarschijnlijk het verwijt van te groote beknoptheid niet ontgaan kan, doch in allen gevalle beter was dan het tot nog toe geleverde ${ }^{1}$. Hij liet daaraan eenige beschouwingen over de letterkunde voorafgaan, die niet bepaald als "reclame" kunnen gelden voor de Maleische literatuur. Trouwens van "reclame" was Pijnappel niet thuis; hetgeen hij voor waar hield, uitte hij zonder schroom. Zoo ook bij de aanvaarding van het Hoogleeraarsambt aan deze Universiteit in 1877. Maar toch schreef dezelfde man, die zoo weinig voorliefde voor de Maleische literatuur toonde, een keurig opstel over de Maleische pantoen's in het "Feestnummer" der Bijdragen (nog nader door hem uitgewerkt te vinden achter zijn laatste Grammatica) bij gelegenheid van het Orientalisten-Congres in 1883 te Leiden. Scherpzinnig (doch acutius quam verius?) brengt hij het woord pantoen als krama-vorm in verband met het Javaansche pari, van paribasan, een soort raadsel-

1 Sinds maakte de uitbreiding der verzameling van Mal. HSS. een nieuwe Beschrijving onontbeerlijk en zijn wij in het bezit van een beter en uitvoeriger Catalogus saamgesteld door Dr. H. H. Juynboll, Jeiden, Brill 1899. 
spreuken die in aard eenigszins met de Maleische pantoen's overeenkomen.

Bij diezelfde gelegenheid sprak hij op mijn aandringen "Over de wortelwoorden in de Maleische taal" als inleiding tot het door mij gekozen onderwerp "over de wortelwoorden in de Javaansche taal."

In Bijdr. 1872 vindt men nog van Pijnappel's hand : "Eenige aanmerkingen op Wallace's Insulinde". Hij opperde daarin bedenkingen tegen de door dezen beroemden natuurvorscher uitgedachte en door Veth met vele anderen destijds overgenomen theorie omtrent de splitsing van Insulinde in een Indisch en Australisch gewest. Later is die theorie op geologische en zoologische gronden sterk aan het wankelen gebracht. ${ }^{1}$

Eindelijk, in de Bijdr. van 1875 en 1877 komen twee recensie's van Pijnappel voor. Ten eerste eene beoordeeling van Versteeg's Atlas; waarbij Pijnappel noodig vond op te komen voor "zuiver" Maleisch en aanmerking te maken op verschillende gebrekkige Maleische vertalingen van Hollandsche benamingen. Om een voorbeeld te nemen - dat hij de vertaling van "wereldkaart" met gambar doenia "afbeelding van deze wereld [tegenover de toekomstige]" in plaats van met pěta boemi wraakt, zal niemand aan vitzucht kunnen toeschrijven. Ten tweede een recensie van de uitgaaf der "Kalila en Damina" door prof. Gonggrijp. Pijnappel gispt de wijze waarop de auteur den tekst heeft saamgesteld en brengt gewichtige bedenkingen in het midden tegen enkele grammaticale beschouwingen die de schrijver aan zijń werk heeft toegevoegd. Pijnappel, die als het te pas komt, gaarne eens een aardigheid ten beste geeft, herinnert de reden, waarom Roorda de door hem voorgestelde transcriptie van de $t j$ en $d j$ met $t s j$ en $d s j$ onnoodig zou gevonden hebben; dat kwam, omdat Roorda bij het uitspreken van die medeklinkers op zijn friesch toch den sisklank deed hooren en b.v. ons woord "strootje" uitsprak "strootsje".

Tot zoover wat Pijnappel in de Bijdragen schreef. Nu moet ik nog vermelden eene korte Beoordeeling van hem der Handleidingen van dr. de Hollander voor het Maleisch en Javaansch in de Gids van 1849 en een stukje van hem in datzelfde Tijdschrift "Itets over ...Javaansche poëzy" naar aanleiding van Roorda van Eysinga's vertaling der Brata-Joeda. Om te kunnen beoordeelen in hoeverre

1 Zie het duidelijke résumé over deze kwestie bij van der Lith, Nederlandsch Oost-Indië bl. 11 volgg. 
die vertaling aan het origineel beantwoordt, geeft Pijnappel een stuk er van en daarnaast een woordelijke overzetting. In de Gids van 1865 staat voorts een zeer lezenswaardig artikel van zijne hand (mij in 1877 toen ik meende ook een woordje te moeten meepraten, tot mijn schade en schande onbekend) over het $\mathrm{zg}$. "hoog-Maleisch", en in die van 1874 een stuk getiteld: "de Rijks-Instelling van Onderwijs in Indische taal-, land-en Volkenkunde te Leiden". Daar het de "question brûlante", de opleiding der Indische ambtenaren geldt, wijs ik ook hier nog op drie brochures van Pijnappel's hand dezelfde zaak betreffende, nl.: "de Koninklijke Akademie te Delft" enz. Amsterdam 1859, "Drie Stellingen over de opleiding der Ind. ambtenaren" 's Gravenhage 1863 en "De Rijks-Instelling te Leiden en de hoogeschool" 's Gravenhage 1868. Met de vermelding van een stukje in het Tijdschrift van Ned.-Indië van 1849 naar aanleiding van een artikel van v. d. Dungen Gronovius over N. O. Borneo is het overzicht der in Tijdschriften opgenomen bijdragen van Pijnappel rakende de Taal-, Land- en Volkenkunde van Ned.Indië vertrouw ik volledig.

Van zijne afzonderlijke werken zijn te vermelden: de twee volgende uitgaven: Reis van Abdoellah van Singapore naar Kalantan, het $4^{\mathrm{e}}$ deeltje uitmakende van de verzaméling: Meursinge's Mal. Leesboek, Brill, Leiden 1865, gevolgd door een $2^{\text {en }}$ druk bij G. Kolff, Leiden 1871. Daar, even als in de 3 eerste deeltjes, geen noten of aanteekeningen zijn toegevoegd, heb ik geen aanleiding om lierbij langer stil te staan.

Menangkabausch-Maleische Zamenspraken; deze in 1872 bij Nijhoff verschenen Uitgave met eene Voorrede en taalkundige opmerkingen van den bewerker, al slaagde deze er niet in de gesprekken geheel verstaanbaar te maken, mag eene belangrijke bijdrage gerekend worden tot de kennis van het toen nog zoo weinig bekende dialect.

Een waardeering van hetgeen Pijnappel meer bepaald voor de kennis der geographie van Ned. Indië geleverd heeft, dank ik aan de welwillendheid van dr. G. J. Dozy, die den $3^{\text {den }}$ druk van Pijnappel's Geographie van Ned. Indië bezorgde.

"Pijnappel's geographische arbeid", schrijft hij, "valt uit den aard "der zaak nagenoeg geheel in zijn Delftsche periode. In $1855 \mathrm{ver}$ "scheen bij Fuhri ('s Gravenhage) de eerste druk van zijn Atlas van "de Nederlandsche bezittingen in Oost-Indië. Dat deze inderdaad voorzag "in een bepaalde behoefte, bewees wel de omstandigheid, dat in 
"1871 een tweede, in 1884 een derde uitgaaf noodzakelijk was. "Wilde men nu over dien atlas een oordeel vellen, dan zou men "onbillijk zijn, zoo men niet in het oog hield, dat de cartographie "toen hier te lande nog op een vrij laag standpunt stond, zoodat "veelal Duitsche atlassen gebruikt werden, terwijl onze Indische "bezittingen bij het onderwijs schromelijk verwaarloosd werden. "Wanneer men dit echter in aanmerking neemt, dan moet men "erkennen, dat met dezen Atlas een belangrijke stap werd gedaan "in de goede richting. Niet alleen omdat daardoor een voortreffelijk "hulpmiddel werd geschonken voor een degelijker studie van den "Indischen archipel, maar ook omdat, waar het eigenlijk alleen "mogelijk was, namelijk bij Java, de natuurkundige gesteldheid "tot haar recht kwam. Naast de topographische was ook een physische "kaart van dit eiland opgenomen, waartoe Dr. F. Junghuhn, de "autoriteit bij uitnemendheid op dit gebied, zijn hulp verleend had.

"Voor de waardeering van Pijnappel's arbeid zijn wellicht de "aan den Atlas toegevoegde. aanteekeningen nog opmerkelijker. "Geheel de nauwgezetheid van den bescheiden geleerde spreekt uit "de volmaakt onpartijdige kritiek, waarmede hij zijn werk bij het "publiek inleidt. Hij deelt mede, welke bestaande kaarten gevolgd "zijn, allereerst die van Melvill van Carnbee. Maar hij merkt op "dat het beter ware geweest zoo hij de kaarten niet door een ander "had moeten laten teekenen. Waar hij een Schoolatlas wil geven, "verklaart hij zich eigenlijk onbevoegd om met zekerheid uit te "maken, welke namen moeten worden opgenomen. Aanmerkingen "die zeker een recensent niet in het hoofd gekomen zouden zijn.

"Bij den Atlas sloot zich weldra een handboek aan. In 1863 "verscheen Prof. Pijnappel's Geographie van Nederlandsch-Indië ('s Gra"venhage, Martinus Nijhoff). Ook op dit boek is van toepassing "wat van den atlas gezegd is. Wel was toen de Hollander's Hand"leiding reeds in wording, maar deze was door haar omvang minder "geschikt voor het doel, dat Pijnappel beoogde, een overzicht, dat "bij het onderwijs kon worden aangevuld. Hieraan voldeed zijn "werk dan ook uitnemend. Geheel in overeenstemming met de "nieuwere opvatting der aardrijkskunde gaf hij een schets van land "en volk, waarbij de staatkundige indeeling geheel, ten opzichte "van Java wel wat te veel, op den achtergrond stond.

"Hoopte hij te geven "eene schets die ook den student eene "aanleiding tot verdere studie kan zijn", ongetwijfeld is die hoop "ten volle verwezenlijkt, en zoo in de laatste veertig jaren onze 
nkennis van ons Indisch gebied aanmerkelijk is uitgebreid door "ijverige studiën onzer bestuursambtenaren, is dit zeker ook voor „een deel aan Pijnappel te danken. Geen wonder dan ook, dat reeds "vijf jaar later een tweede druk van zijn Geographie noodig werd.

"Ware Pijnappel te Delft gebleven, dan zou hij, op den inge"slagen weg voortgaande, op de zich meer en meer ontwikkelende „belangstelling voor land- en volkenkunde zeker een belangrijken "invloed hebben uitğeoefend. Maar zijn verplaatsing naar Leiden "bracht hem voor goed op linguistisch terrein. Hij was niet de "man om iets ten halve te doen, en toen in 1881 de uitgever der "Geographie hem aanzocht een derden druk te bewerken, achtte "hij met zijn gewone bescheidenheid zich daartoe niet meer ge"roepen. De jaren, die verloopen waren sinds hij de eerste hand "legde aan zijne schets, hadden onze kennis van den Indischen "Archipel op zooveel punten verhelderd en verrijkt, dat hị zich "er eerst weer geheel in had moeten werken, en hij gaf er daarom "de voorkeur aan de door hem met liefde opgenomen tak op "jeugdiger schouders over te dragen."

Eindelijk Pijnappel's werkzaamheid op zijn eigenlijk terrein en dus het voornaamste: Pijnappel's taalkundige werken. Uit geen van Pijnappel's werken spreekt zoozeer zijn wetenschappelijk geweten als uit zijne Maleische Grammatica: Telkens zichzelf verbeterende, altijd naar het betere zoekende en tot nader onderzoek opwekkende is het niet de "Meester" die voor zijne "leerlingen", maar de primus inter pares die voor zijn "medestudenten" schrijft. Ja in de voorrede der laatste uitgave verklaart hij zijne vorige Spraakkunsten als van niet meer dan "zeer bescheiden historisch belang", terwijl er toch ook in deze veel belangrijks en oorspronkelijks te vinden is.

Zoo o. a. in de Uitgaaf van 1866 (die van 1862 "voor Eerstbeginnenden", een grammaticale schets die volgens den auteur zelf al "te kort" bevonden is, ga ik met stilzwijgen voorbij) waar hij het voegwoord maka behandelt (\$122). Aan het slot resumeert hij: "maka drukt altijd een nauw verband uit: zonder dat heeft het geen zin. Zoo maar aan het begin van een zin gebezigd zonder eenig doel - als een stopwoordje zouden wij zeggen, wanneer wij een stopwoord vooraan konden stoppen - is het onzin. - Het zou mij niet verwonderen, zoo voortgezet onderzoek leerde, dat maka eigenlijk o orzaak, reden beteekende."

Met opzet kies ik dit artikel niet alleen als voorbeeld van 
Pijnappel's humor, maar ook omdat "voortgezet onderzoek" hem tot het m. i. uitstekende artikel op dat woord in zijn Woordenboek van 1875 heeft geleid. Zijne opvatting is doorgaans oorspronkelijk; het Subjectief Passief van Roorda (door de jongeren "m. i. niet te recht" voor het Maleisch niet aangenomen) heeft reeds bij hem (al is het dan stillen) tegenstand ontmoet. Hij nam het voor het Maleisch niet over. In zijn editie van 1866 zegt hij bij de pronomina $\$ 91$ : "akoe en engkau verliezen onmiddellijk vóor het werkwoord (dat dan ook het actief praefix niet aanneemt) geplaatst, dikwijls hunne eerste lettergreep."

Als Inleiding gaf Pijnappel vóor de Uitgave van zijn Woordenboek van 187 jrammaticale beschouwingen "over de afgeleide woordvormen en hunne beteekenissen." Ook hier weer veel nieuws en belangrijks, niet het minst het hoofdstuk over de "Zamenstelling van Woorden." Doch het sterkst komt Pijnappel's eigenaardige wetenschappelijke behandeling der tot de Maleische Spraakkunst behoorende materie uit, in de laatste Uitgave van zijne Grammatica [1888]. De titel reeds duidt aan, hoe hij zijne taak opvat. Hij geeft een leiddraad, geen practische handleiding voor den aanstaanden Indischen ambtenaar, maar voor den "student", den beoefenaar van het Maleisch.

Zeer belangrijk o. a. komen mij daarin voor het hoofdstuk over de copula en dat over de telwoorden: In $\S 39$ redeneert hij op zijne eigenaardig philosophische wijze: "De werkwoorden zijn wel de praedicaatswoorden bij uitnemendheid, doch ook andere woorden kunnen als praedicaten fungeeren. In dat geval wordt in vele talen het werkwoord zijn voor copula gebruikt, d.w. z. o m het bestaan van een verband tusschen subject en predicat uit te drukken. Daar echter dit verband toch bestaat, al wordt het niet door de copula aangewezen, zoo is het gebruik van deze eigenlijk overbodig. Hoe zulk een gebruik nochtans in zwang kan komen, dat blijkt bv. uit het Maleisch. Hier worden namelijk als het een toestand geldt ada, en als er een iets-te-zijn bedoeld wordt, djadi, zóo gebruikt dat wij beide door de copula zij n vertalen kunnen. Zoo bet. ada baik (hij) bevindt zich wel, hij is wel - maar niet als er van een qualiteit gesproken wordt: men zegt termpat itoe baik, die plaats is goed," enz., en in $\S 55$ geeft hij $\operatorname{van} s a$ de volgende grondbeteekenis: ook $s a$. beteekent niet oorspronkelijk é e $\mathrm{n}$, maar dient eigenlijk om te individualiseeren d.w. z. om iets voor te stellen als op zichzelf staande eenheid samengevat: zoowel begrensd, onderscheiden van wat er buiten is, 
als constant aan zichzelf gelijk. Uit die beteekenis van $s a$ vloeit het veelzijdig gebruik van dit woordje voort; en later $\left(6^{\circ}\right)$ : "Daar de getallen abstracte begrippen zijn, zoo is het telwoord éen dat ook. Dat iets slechts éen is, ligt niet in het begrip van eenig ding zelf, is er geen qualiteit van. Wel kan het de qualiteit van iets zijn, dat het altijd uit een bepaald aantal deelen bestaat, zooals de hand uit vijf vingers. Maar in de beteekenis van op zichzelf, van individu, ligt alleen opgesloten het begrensd zijn tegenover de veelheid van alle andere dingen te zamen, en dus een enkelvoud van wezen, niet van aantal, iets dat wij door het onbepaalde 'n of door 'n zeker uitdrukken, niet door éen."

Doch zelfs nu is Pijnappel nog niet over zich zelf voldaau en tracht hij nog wat beters of volledigers te geven in de aan het slot bijgevoegde Aanteekeningen.

Bij den in het Maleisch gewonen regel, dat het adjectief na het substantief komt teekent hij als uitzondering daarop aan: "De pronominale adjectiva ini en itoe staan dikwijls vóor het hoofdwoord", en laat dan de verder strekkende woorden volgen: "Geen taal, die haar oorspronkelijke zuiverheid bewaarde en zonder daarom nog, als het niet noodig is, het voorbeeld te geven, zoo is het aan den anderen kant een vergeefsch en daarom dwaas werk zich te verzetten tegen een macht die sterker is dan de onze: in het Maleisch evenzeer als in onze eigen taal enz.

Om de verdiensten van Pijnappel ten opzichte van de Maleische lexicographie te beoordeelen, moet men rekening houden met de middelen, die hem ten dienste stonden. Zelf heeft hij zijne woordenkennis door navragen niet kunnen vermeerderen, hij heeft die moeten putten uit lectuur of door kritisch gebruik te maken van door anderen plaatselijk opgedane kennis.

Voor de eerste Uitgave van zijn Maleisch Woordenboek was zijn voornaamste bron het Woordenboek van (Marsden) Elout, later het Supplement van Klinkert en voor een deel het Woordenboek van v. d. Wall. Hoe voorzichtig Pijnappel die eerste bronnen heeft gebruikt blijkt al dadelijk uit den zooveel geringeren omvang van Pijnappel's uitgave en dat, niettegenstaande hij plaatsruinte besteedde aan het vergelijken met zustertalen - iets, dat hij echter later en volgens van der Tuuk terecht, naliet.

Een grooten steun ontving Pijnappel door Klinkert's Supplement op zijn Woordenboek. Doch hoewel hij de groote verdiensten van 
dat werk erkende, bleek in Bijdr. $3^{\text {e }}$ Reeks $V$, uit zijne daarop gegeven Aanteekeningen dat hij het op menig punt met dezen "uitstekenden kenner van het Maleisch" (Pijnappel in Bijdr. 1875 bl. 375) niet eens was en lichtte hij breedvoerig zijn afwijkende opinie toe. Belangrijk is het fijne onderscheid in beteekenis door hem gemaakt tusschen hendaq en maoe. Klinkert omschrijft het eerste met "wenschend willen" het tweede met "volstrekt willen". Volgens Pijnappel daarentegen ziet het eerste op de uitvoering (het Grieksche $\mu \varepsilon \lambda \lambda \omega \omega$ ), het tweede op de gezindheid (Grieksch

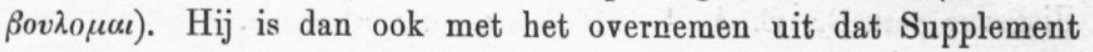
in zijne editie van 1875 hier en daar (misschien te) spaarzaam geweest. Van geen overwegenden aard kon de invloed van v. d. Wall zijn op die Uitgave, daar Pijnappel daarbij maar eenige vellen van diens werk te zijner beschikking had.

Het exemplaar van Pijnappel's Woordenboek van 1863, doorschoten, en van Pijnappel's eigenhandige Aanteekeningen voorzien, ${ }^{1}$ bewijst hoe zelfstandig Pijnappel de Uitgave van 1875 bewerkt heeft. Om een greep te doen onder verschillende soorten van woorden wijs ik op woorden als tělah, datang, dapat, déngan, patoet, jang en maka, artikels, die in het beste Woordenboek eene eereplaats verdienen. In de laatste editie van 1884, niettegenstaande Pijnappel toen het geheele Woordenboek van v. d. Wail tot zijn dienst had, waaruit hij ook wel tot verbetering maar toch veel meer tot aanvulling heeft kunnen overnemen, zijn dan ook die artikels, en zij behooren tot de belangrijkste ook in omvang, zoo goed als onveranderd gebleven en leggen getuigenis af van zijn meesterlijke redactie.

Ziedaar een overzicht van Pijnappel's belangrijken en verdienstelijken arbeid. Als oud-collega en vriend werd ik geroepen daarvan verslag te geven. Hoewel hij gewerkt heeft op een terrein dat, strikt genomen, het mijne niet is, hoop ik er toch in geslaagd te zijn hier en daar zijne verdiensten in het ware licht te stellen.

Leiden, Januari 1902.

${ }^{1} \mathrm{Ik}$ heb het te danken aan de HH. Burgersdijk en Niermans alhier. 


\section{LIJST DER GESCHRIFTEN EN WERKEN VAN \\ Dr. J. Pijnappel Gzs.}

Beoordeeling van 2 werken van dr. de Hollander . Gids I 1849. Over een artikel van v. d. Dungen Gronovius over

N. O. Borneo . . . . . . . Tijdschr. v. Ned. Indië "

Iets over het Kawi en de Javaansche poëzij . . . Gids II "

Uitgever van Dr. C. A. L. M. Schwaner's "Borneo.

Beschrijving van het stroomgebied van den Barito

en reizen ... gedaan in de jaren 1843-1847".

Amsterdam, P. N. van Kampen. 2 dln. 1853-54.

Overzigt van de geschiedenis der Nederlanders in

O. Indië . . . . . . . . . . . . . . Bijdr. 1854.

Bijdrage tot de kennis der Chin. geheime genootschappen .

Inhoudsopgaven der 27 eerste deelen van het Tijdschrift voor Ned. Indië

Ethnologische Studiën (nl. bespreking van Earl's "Papuans") . . . . . . . . . . . . . . . . " " "

Inhoudsopgaven der 27 eerste deelen van de Verh. Bat. Gen., van "de Oosterling", het Indisch Magazijn en het Indisch Archief .

1855.

Atlas van de Ned. bezittingen in O. Indië. 's Hage, Fuhri "

Uitgever van Reinwardt's "Reis naar het Oostelijk gedeelte van den Ind. Archipel in het jaar 1821".

Amsterdam, Fred. Muller 1858.

Bijdrage tot de geschiedenis der Vulkanen in Ned.Indië Bịdr. 1859.

De Koninklijke Akademie te Delft als inrigting tot opleiding van Indische ambtenaren beschouwd. Amst., Fred. Muller "

Over het Arabisch-Maleische alphabet . . . . . Bijdr. 1860. Beschrijving van het Westelijk gedeelte der Z. en O. afdeeling van Borneo .

Maleische Spraakkunst voor Eerstbeginnenden.

's Gravenhage, Nijhoff 1862.

Maleisch-Hollandsch Woordenboek. $1^{\text {ste }}$ druk, Amsterdam, Fred. Muller, Haarlem, Enschedé en Zonen. 1863.

Geographie van Ned. Indië. 1 ${ }^{\text {ste }}$ druk. 's Gravenhage, Nijhoff " 
Drie Stellingen over de opleiding der Indische ambtenaren . . . . . . . 's Gravenhage, Nijhoff 1863. Hoog-Maleisch. . . . . . . . . . . . . Gids IV 1865.

Reis van Abdallah enz. van Singapore naar Kalantan . . . . . . . . . . . Leiden, Brill " Maleische Spraakkunst . . . . . 's Gravenhage, Nijhoff 1866. Geographie van Ned. Indië. $2^{e}$ druk. " Nijhoff 1868.

De Rijksinstelling van Onderwijs in Ind. taal- land- en volkenkunde en de hoogeschool . . . . . . . " N Nijhoff "

Aanteekeningen op H. C. Klinkert's Supplement op mijn Mal. Woordenboek . . . . . . . . . Bijdr. 1870.

Catalogus der Mal. handschriften in de Bibliotheek der Leidsche Akademie

Reis van Abd-Allah enz. 2de druk. . . . Leiden, Kolff 1871. Si-Daoed Radja Medan. Mĕnangkabausche-Maleische

Zamenspraken . . . . . . 's Gravenhage, Nijhoff 1872. Over de kennis, die de Arabieren vóor de komst der Portugeezen van den Ind. Archipel bezaten . . Bijdr. " Enkele aanmerkingen op Wallace's Insulinde. . . " " Atlas. $2^{\text {de }}$ uitgaaf . . . . Amsterdam, Van Kampen "

De Rijksinstelling van Onderwijs in Ind. taal- landen volkenkunde te Leiden 1864-1874 . . . . Gids I 1874. Maleisch-Hollandsch Woordenboek. $2^{\mathrm{e}}$ druk. Haarlem, Enschedé \& Zonen, Amsterdam, Fred. Muller 1875.

De Mal. atlas van den heer W. F. Versteeg . . . Bijdr. " Eene nieuwe uitgave van de Kalila . . . . . . " 1877.

Het recht en de waarde der beoefening van het Maleisch en in het algemeen van de Polynesische talen als vak van hooger onderwijs. Redevoering bij de aanvaarding van het hoogleeraarsambt te Leiden . . . . . . . . . . . Leiden, Brill "

Geographie van Ned. Indië, herzien door dr. G. J. Dozy. 's Gravenhage, Nijhoff 1881.

Over de Maleische pantoen's in feestnummer Bijdr.

Atlas van de Ned. bez. in O. Indië. 3e uitgaaf. 's Gravenhage, Nijhoff 1883. Amsterdam, Van Kampen " Maleisch-Hollandsch Woordenboek. $3^{\mathrm{e}}$ druk. Haarlem, Enschedé \& Zonen, Amsterdam, Fred. Muller 1884. 
Over de wortelwoorden in de Maleische taal in "Actes du 6 me Congrès International des Orientalistes IVe Partie."

Leiden, Brill 1885.

Maleische Grammatica, niet alleen voor hen die voor eenig practisch doel die taal noodig hebben, maar vooral voor hen, die belang stellen in de taalkunde in het algemeen, ter opwekking tot verdere oefening en beoefening. Amsterdam, Frederik Muller, Haarlem, Enschedé en Zonen $1888^{1}$.

1 De volledigheid dezer lijst dank ik voor een goed deel aan onzen ijjverigen adjunct-secretaris G. P. Rouffaer.

Nog schreef dr. Pijnappel de volgende werken; die echter als niet behoorende tot het gebied der T. L. en V. van Ned. Indië door mij niet besproken werden:

Ibn Callicanis Vitae ex lexico biographico, quae non extant nisi in Cod. Amst. Amst. Spin 1845 (proefschrift), "de Vrije wil", Joh. Muller Amst. 1886.

Nehalennia, eene oudheidkundig-historische studie, J. C. W. Altorffer Middelburg 1891.

„Leven", een Wereldbesehouwing Leiden, Brill 1894. 